\title{
Acute intoxication cases admitted to the emergency department of a university hospital
}

\author{
Ertugrul Kaya ${ }^{1}$, Aylin Yilmaz ${ }^{2}$, Ayhan Saritas ${ }^{3}$, Serdar Colakoglu ${ }^{4}$, Davut Baltaci ${ }^{2}$, Hayati Kandis ${ }^{3}$, \\ Ismail Hamdi Kara ${ }^{2}$ \\ ${ }^{1}$ Department of Pharmacology, Faculty of Medicine, Duzce University, Duzce, Turkey \\ ${ }^{2}$ Department of Family Medicine, Faculty of Medicine, Duzce University, Duzce, Turkey \\ ${ }^{3}$ Department of Emergency Medicine, Faculty of Medicine, Duzce University, Duzce, Turkey \\ ${ }^{4}$ Department of Anatomy, Faculty of Medicine, Duzce University, Duzce, Turkey
}

Corresponding Author: Ayhan Saritas, Email: a_saritas_@hotmail.com

BACKGROUND: This study aimed to describe the clinical and socio-demographic aspects of acute poisoning in 2010 in Duzce City, Northwest Anatolian Region of Turkey.

METHODS: Acute poisoning was due to the intentional ingestion of drugs in young and adult people $(\geq 16)$, who were treated at the Emergency Service of Duzce University Medical Hospital, Turkey from January 1, 2010 to December 31, 2010. In this retrospective and descriptive study, 95 patients were diagnosed with intoxications and 30 of them intentionally ingested drugs to commit suicide. Records of the patients diagnosed with intoxication were obtained from the Clinical Archive of the hospital. Their diagnoses were established according to the International Statistical Classification of Diseases and Related Health Problems. Codes X60-X84 of this classification were used to classify self-infringed drug injuries and drug poisoning.

RESULTS: In this series, $35(36.8 \%)$ patients were male and 60 patients $(63.2 \%)$ female. The male/female ratio was $1.0 / 1.7$. The mean age of the patients was $33.1 \pm 14.2$ years; $17(17.9 \%)$ patients were below 20 years old and 9 (9.5\%) were older than 50 years. Of these patients, 29 $(30.5 \%)$ were single, $7(7.4 \%)$ divorced or separated, and $59(62.1 \%)$ married. Their mean time for admission to the emergency service after the incident was $208 \pm 180$ (15-660) minutes. The mean time for admission to the emergency service for patients with food intoxication after the incident was $142 \pm 160$ minutes, for those with drug intoxication $173 \pm 161$ minutes, for those with carbon monoxide (CO) intoxication $315 \pm 209$ minutes, and for those with undefined intoxication $289 \pm 166$ minutes $(P=0.005)$. Most of the intoxication cases occurred in winter $(41.1 \%, 39$ of 95 patients). Admissions to the emergency service were most common in December and April (21 and 16 of 95 patients, respectively). Sixty-five (68.4\%) cases were involved in non-deliberate poisoning, whereas $30(31.6 \%)$ were involved in deliberate poisoning. Twenty-six of the 95 patients with acute poisonings had mortality risk at admission, however only one died from $\mathrm{CO}$ intoxication in the emergency service $(1.1 \%)$. Suicide attempts were more common in females than in males (21 of 30 patients, $70 \%$, $P<0.05)$.

CONCLUSION: In Duzce City of Turkey, most intoxication cases occurred in winter, especially in December. They had non-deliberate poisoning, but deliberate poisoning in suicide attempts was more common in females than in males.

KEY WORDS: Emergency service; Poisoning; Suicide attempt

World J Emerg Med 2015;6(1):54-59 DOI: 10.5847/wjem.j.1920-8642.2015.01.010 


\section{INTRODUCTION}

There are marked differences in the patterns of poisoning between centers of various countries. In developed countries, the annual incidence of both non-deliberate and deliberate human poisoning varies between 0.2 and 9.3 poison exposures per 1000 people, and continues to increase annually worldwide owing to decreasing safety and also increasing reporting and registry. ${ }^{[1,2]}$

The rates of poisoning-related visits to emergency departments (EDs) vary substantially throughout the world, and range from $0.076 \%$ to $0.7 \%$ annually. ${ }^{[2,3]}$ Studies $^{[3,4]}$ in western countries revealed that the annual rate of poisoning-related ED visits was about $0.26 \%$. It was reported that the poisoning rates in male and female patients were $55.8 \%$ and $44.2 \%$, respectively, as $63 \%$ of the patients were under 40 years of age. ${ }^{[5]}$ During the 1990-2001 period, the death rate from poisoning in the United States increased at a rate of $56 \%$, from 5.0 per 100000 population in 1990 to 7.8 in 2001 . Of 22242 poisoning deaths in 2001,14078 (63\%) were unintentional. $^{[6]}$

This retrospective and descriptive study aimed to describe the clinical and socio-demographic aspects of acute poisoning and the patterns of poisoning in Duzce City, Northwest Anatolian Region of Turkey in 2010.

\section{METHODS \\ Setting}

The study was carried out regarding sociodemographic and clinical issues related to drug intoxications and suicide attempts by the intentional ingestion of drugs in young and adult populations $(\geq 16$ years old) treated at the Emergency Service of Duzce University Hospital, Turkey from 1 January 2010 to 31 December 2010. This study was approved by the Ethical Committee of Duzce University Medical Faculty (number: 2012/292).

\section{Patients}

A total of 95 patients were diagnosed with intoxications. In this series, 30 patients intentionally ingested drugs to commit suicide. Records of patients diagnosed with drug intoxication were obtained from the Clinical Archive of the hospital. The diagnoses of the patients were established according to the International Statistical Classification of Diseases and Related Health Problems. Search key words are codes X60-X84 of this classification, which classify self-infringed drug injuries and drug poisoning (these codes involve intoxication, poisoning, suicide, drug overdose but not alcohol). ${ }^{[7]}$ There were no any homicidal intoxications.

\section{Outcome measures}

Registries of patient diagnoses in the ED were revised in relation to drug intoxication diagnoses, since the first contact and immediate management occurred in this department. Initially, the patients were treated in the ED and, if required, an evaluation was performed by medical staff in services such as psychology, psychiatry, intensive care unit and other departments. Sufficient data were collected to meet the objective of this study. The types of poisonous compounds, age and gender of the patient, marital status, suicidal purpose, hospitalization time, place the patient comes from, and symptoms observed were investigated.

\section{Statistical analysis}

Statistical analyzes were made by the SPSS 11.5 software. Contineous variables (age, time after intoxication and time of intoxication) were presented as as mean $\pm \mathrm{SD}$. Before analyses, the Kolmogorov-Smirnov normality test was applied. Age was normally distributed $(P=0.150)$, but time after intoxication and the time of intoxication were not $(P=0.019$ and $P<0.01)$. Categorical variables were expressed as number and percentage. Numeric variables which were normally distributed were compared by one-way ANOVA (Post Hoc Bonferroni), and the Kruskal-Wallis test was used for those which were not normally distributed. The Chi-square test or Fisher's exact test was used to compare categorical variables between groups. A $P<0.05$ was considered statistically significant.

\section{RESULTS}

In the 95 patients, $35(36.8 \%)$ were male and 60 (63.2\%) female. The male/female ratio was 1.0/1.7. The mean age of the patients was $33.1 \pm 14.2$ years; 17 (17.9\%) patients were under 20 years old and $9(9.5 \%)$ were older than 50 years. In the all patients, $30.5 \%$ $(n=29)$ were single, $7.4 \%(n=7)$ were divorced or separated, and $62.1 \%(n=59)$ were married. The mean time for admission to the emergency service after the incident was $208 \pm 180$ (15-660) minutes, or $152 \pm 165$ minutes for male and $190 \pm 169$ minutes for female suicide cases $(P=0.01)$ (Figure 1). 


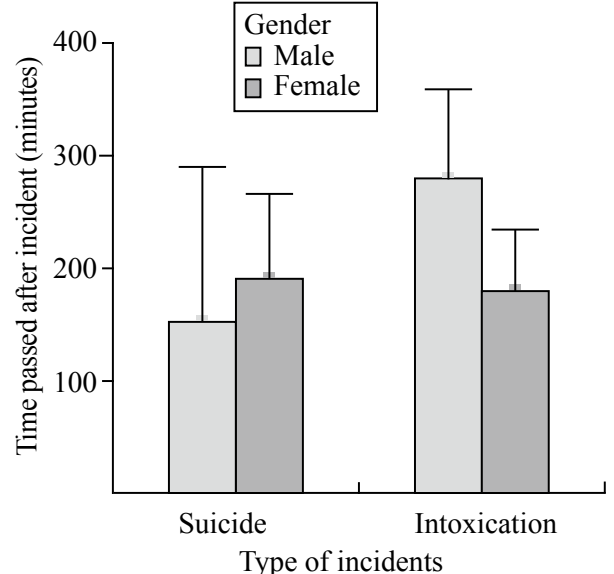

Figure 1. The mean time for admission to the emergency service after the incident according to the types of incident.

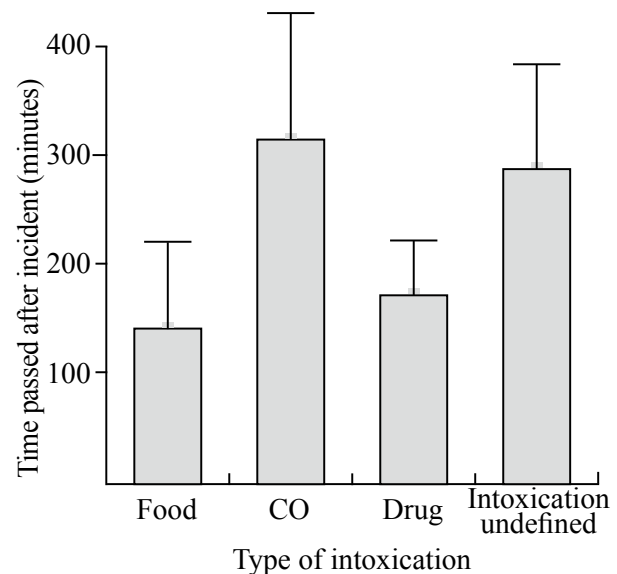

Figure 2. The mean time for admission to the emergency service after the incident according to types of intoxication.

The mean time of admission to the emergency service for patients with food intoxication after the incident was $142 \pm 160$ minutes, for those with drug intoxication $173 \pm 161$ minutes, for those with carbon monoxide (CO) intoxication $315 \pm 209$ minutes, and for those with undefined intoxication $289 \pm 166$ minutes $(P=0.005)$ (Figure 2).

Of the 95 patients, $39(41.1 \%)$ had intoxication in winter. In this series, 21 and 16 patients were admitted to the emergency service in December and April, respectively (Figure 3).

Sixty-five $(68.4 \%)$ patients had non-deliberate poisoning, whereas $30(31.6 \%)$ had deliberate poisoning. Of the 95 patients with acute poisonings, 26 had severe impairment of vital signs at admission, but only one patient $(1.1 \%)$ died from CO intoxication at the emergency service. Being transferred to the ED, the patient was in asystole. The defined suicide attempts

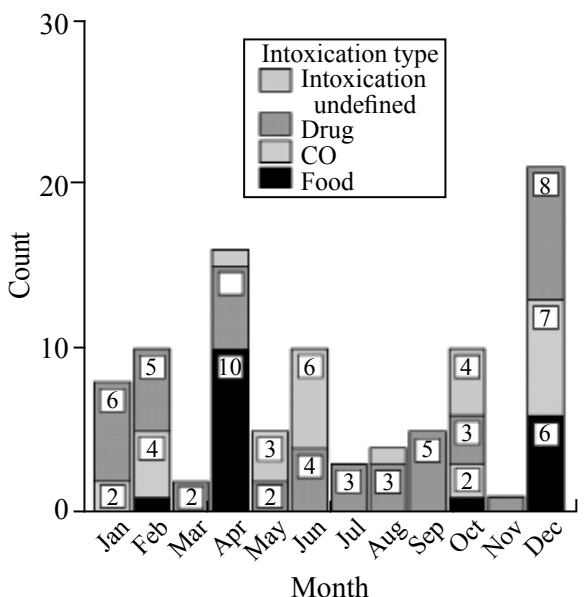

Figure 3. The distribution of patients according to months and types of intoxication at admission to the emergency service.

Table 1. Patient characteristics according to types of intoxication

\begin{tabular}{|c|c|c|c|}
\hline \multirow[t]{2}{*}{ Parameters } & \multicolumn{2}{|c|}{ Types of intoxication } & \multirow{2}{*}{$P$ value } \\
\hline & \multicolumn{2}{|c|}{$\overline{\text { Suicidal }(n, \%) \text { Non-deliberate }(n, \%)}$} & \\
\hline \multicolumn{4}{|l|}{ Marital status (male) } \\
\hline Married & $3(10.0)$ & $16(24.6)$ & \multirow[t]{3}{*}{$>0.05$} \\
\hline Single & $4(13.3)$ & $8(12.3)$ & \\
\hline Separated/divorced & $2(6.7)$ & $2(3.1)$ & \\
\hline \multicolumn{4}{|l|}{ Marital status (female) } \\
\hline Married & $10(33.3)$ & $30(46.2)$ & \multirow[t]{3}{*}{$<0.05$} \\
\hline Single & $10(33.3)$ & $7(10.7)$ & \\
\hline Separated/divorced & $1(3.3)$ & $2(3.1)$ & \\
\hline \multicolumn{4}{|l|}{ Mortality risk } \\
\hline Yes & $13(43.3)$ & $38(58.5)$ & \multirow[t]{2}{*}{$<0.01$} \\
\hline No & $17(56.7)$ & $52(41.5)$ & \\
\hline \multicolumn{4}{|l|}{ Outcome } \\
\hline Discharge & $14(46.7)$ & $49(75.4)$ & \multirow[t]{4}{*}{$<0.01$} \\
\hline Hospitalization & $13(43.3)$ & $9(13.9)$ & \\
\hline Death & 0 & $1(1,5)$ & \\
\hline Referred & $3(10.0)$ & $6(9.2)$ & \\
\hline \multicolumn{4}{|l|}{ Intoxication type } \\
\hline Food & 0 & $18(27.7)$ & \multirow[t]{4}{*}{$<0.01$} \\
\hline $\mathrm{CO}$ & 0 & $15(23.1)$ & \\
\hline Drug (medical) & $30(100)$ & $17(26.1)$ & \\
\hline Undefined & 0 & $15(23.1)$ & \\
\hline Total & $30(31.6)$ & $65(68.4)$ & $95(100)$ \\
\hline
\end{tabular}

were related to drug intoxication (30 suicide patients, $31.6 \% ; P<0.0001$ ) (Table 1).

Female suicide attempts predominated in all suicide cases ( 21 of 30 suicide cases, $70 \%, P=0.048$ ), and single women were prominent in female suicide cases ( 10 of 21 female suicide cases, $47.6 \%, P=0.037$ ).

\section{DISCUSSION}

Güloğlu and $\mathrm{Kara}^{[8]}$ reported 170 patients with intoxication, with a mean age of 23.3 years. Of the patients, $63(37.1 \%)$ were under 20 years old and 147 
$(86.5 \%)$ were under 30 years. Most of the patients had intoxication in summer (93 of 170 patients). They were admitted to the hospital in April, May and July (24, 26 and 30 patients, respectively). Sixty-two (36.5\%) of the patients suffered from non-deliberate poisoning, whereas $108(63.5 \%)$ from deliberate poisoning. In suicide attempts, intoxications were common in females ( 77 cases, $71.3 \%$ ) as well as in unmarried persons (74 cases, $68.5 \%)$. In the 170 patients, only two (1.2\%) died from pesticide poisoning and drug abuse respectively. ${ }^{[8]}$

The rate of suicide in Turkey was 2.2/100 000 persons and a total of 28408 suicide deaths were reported in the period of 1974-1998. The rate of suicide was higher in men than in women $(2.7 / 100000$ persons vs. $1.7 / 100000$ persons), and the male/female ratio was $1.5 / 1$. In the suicide deaths, $37.7 \%$ were single, $9.5 \%$ were divorced or separated, and $52.8 \%$ were married. Of these deaths, $62.1 \%$ were city dwellers, and $37.9 \%$ were from rural area. However, suicidal attempts were especially prominent in young depressive or pessimistic females aged 15-24 years. ${ }^{[9]}$

According to a German study ${ }^{[10]}$ more than $40 \%$ of the youths and adolescents committed suicide and the suicide victims were predominantly male $(68.5 \%)$.

A study ${ }^{[11]}$ from Turkey reported that $179(0.7 \%)$ of the patients who were admitted to the ED in a year suffered from acute adult poisonings and the poisoning rate was the highest in patients aged 16-25 years. Most of the patients admitted to the ED were females $(68.8 \%)$. The poisonings due to oral intake accounted for $78.8 \%$ of the patients. The common cause of poisoning was deliberate self-poisoning (58.6\%), followed by non-deliberate poisoning (39.1\%). Of deliberate selfpoisonings, $41(36.6 \%)$ occurred in males and $71(63.4 \%)$ in females. The mean age of the female patients who had suicidal attempts was 27 years. Another study ${ }^{[12]}$ showed that the female-to-male ratio of poisoning-related ED visitors was $3 / 1$, and the majority of patients $(63.6 \%)$ were less than 25 years old.

Ozkose et $\mathrm{al}^{[13]}$ evaluated 228 patients with acute poisonings (180 patients with suicide poisoning) who were admitted to the emergency center, accounting for $0.7 \%$ of all emergency admissions. They reported that the female/male ratio was $3 / 1$ and that most (63.6\%) of the patients were below the age of 25 years. In our study, $0.7 \%$ of the patients with acute poisonings were admitted to the ED. Most (93 patients, 54.7\%) of the patients with intoxication were admitted in summer. The vast majority of the patients were female and under 30 years old, and the female/male ratio of the patients was 1.0/3.5.
Sixty-two $(26.5 \%)$ patients were due to non-deliberate poisonings, whereas $108(63.5 \%)$ were due to suicidal poisonings. In patients with suicidal poisonings, $68.5 \%$ were unmarried and $71.5 \%$ were female.

A multi-center study ${ }^{[14]}$ prospectively analyzed cases from 14 emergency departments in 14 randomized days between February and April 2000. The study included all age groups and all kinds of acute intoxication (including alcohol), except food-related cases, inserted foreign bodies and deaths before arrival at the ED. A total of 419 patients were recorded, accounting for $0.66 \%$ of ED visits. The incidence of intoxication was higher at weekends or on mondays. The mean age of the patients was 33 years. In this series, males accounted for $56 \%$, and $34.2 \%$ arrived to the ED within the first 2 hours. Approximately $80 \%$ of the patients were treated as outpatients, $3.7 \%$ were admitted to the ICU, $6.7 \%$ were hospitalized, and $0.2 \%$ died. The longer arrival time of our patients was due to the tertiary status of our hospital since they were initially taken to other hospitals.

The mortality rate of patients after intoxications ranged from $0.24 \%$ to $27 \% \cdot{ }^{[15-17]}$ Maier et al ${ }^{[18]}$ reported that 190 patients who attempted suicide by severe medicinal intoxication in Basel were admitted to the ICU between January 1, 1998 and December 31, 2001. These patients had psychiatric disorders. By the end of 2005, about half of the 118 patients who were followed up in the outpatient department committed further suicide attempts. In 28 deaths, 6 were due to suicide. The lower mortality rate in our study was due to a few suicidal cases.

A large cohort study ${ }^{[19]}$ reported 85398 cases of acute intoxications in Poland in 2009. In 42002 cases, further hospital treatment was not needed. Ethanol poisoning was common in patients treated at the emergency department. In 2009, there were 491 (1.13\%) deaths caused by acute intoxications. Thus, the mortality rate in critical care departments was $14.41 \%$, whereas it was $1.13 \%$ in toxicology centers. In our study, no ethanol intoxication case was observed. The reason may be the rare consumption of ethanol in Turkey compared with western countries.

Goksu et $\mathrm{al}^{[11]}$ reported that the mean ICU stay was $3.8 \pm 1.1$ days. OP, household product and carbon monoxide poisonings gave a mortality rate of $2.8 \%$. In another study, ${ }^{[8]}$ nonspecific treatment was given to $78.2 \%$ of patients with such poinsonings. $50 \%$ of our patients were discharged from the hospital on the third day of hospitalization and $45 \%$ of the patients were discharged between the third and seventh day. There 
were only two deaths $(1.2 \%)$ in the 170 patients with acute poisonings during hospitalization. One death was due to pesticides and the other was due to drug abuse.

Patients with poisoning present with manifestations ranging from gastrointestinal symptoms (nausea, vomiting, and diarrhea) to severe neurological manifestations (fasciculations, seizures, neuromuscular weakness, and paralysis) or cardiac manifestations (arrhythmia and conduction disturbances, even respiratory and cardiac arrest). ${ }^{[20]}$

Güloğlu's study ${ }^{[8]}$ reported that patients were hospitalized especially in summer, April (24 patients, $14.1 \%$ ), May (26 patients, $15.3 \%$ ) and July (30 patients, $17.7 \%$ ). Because Southeast Anatolian region has an agriculture-based population, agricultural laboring and use of herbicides are quite often in summer. Similarly in our study, the frequent use of herbicides may increase the rate of intoxication in June.

In North-West Anatolia, $\mathrm{CO}$ poisoning is another cause of intoxication in winter because of stove heating common in houses. ${ }^{[21]}$ In our study, most intoxication cases were seen in winter especially in December (21 patients, 22.1\%) (Figure 3). This finding may be related to $\mathrm{CO}$ intoxication.

In our region, food intoxication is caused by bitter-honey intoxication. This honey is produced by bees from the nectar of Rhododendron luteum and Rhododendron ponticum containing grayanotoxin. With heart symptoms including bradycardia, hypotension and syncope, the patients with bitter honey intoxication were admitted to the emergency department. Bitterhoney intoxication is encountered more common between April and June. ${ }^{[22]}$ In our study, the increase of food intoxication cases in these months may be also due to bitter-honey intoxications.

Our study has limitations. First, only patients admitted to the emergency service within a year were examined. Second, the number of patients admitted to one center was limited. Third, a small sample size is insufficient to generalize to other regions of Turkey.

In conclusion, the data of this study may provide important information about the pattern of symptomatic poisoning in a particular region. In Duzce city of Turkey, most intoxication cases occur in winter, especially in December. Most of patients with intoxication are involved in non-deliberate poisoning, whereas deliberate poisoning in suicide attempts was more common in females than in males. Further large scale studies are required.

\section{Funding: None.}

Ethical approval: This study was approved by the Ethical Committee of Duzce University Medical Faculty (number: 2012/292).

Conflicts of interest: The authors have no commercial associations or sources of support that might pose a conflict of interest.

Contributors: Kaya E proposed the study, analyzed the data and wrote the first draft. All authors contributed to the design and interpretation of the study and to further drafts.

\section{REFERENCES}

1 Litovitz TL, Klein-Schwardz W, Caravati EM, Youniss J, Crouch B, Lee S. 1998 annual report of the American Association of Poison Control Centers Toxic Exposure Surveillance System. Am J Emerg Med 1999; 17: 435-487.

2 Hanssens Y, Deleu D, Taqi A. Etiologic and demographic characteristics of poisoning: a prospective hospital-based study in Oman. J Toxicol Clin Toxicol 2001; 39: 371-380.

3 Thomas SH, Bevan L, Bhattacharyya S, Bramble MG, Chew K, Connolly J, et al. Presentation of poisoned patients to accident and emergency departments in the north of England. Hum Exp Toxicol 1996; 15: 466-470.

4 McCaig LF, Burt CW. Poisoning-related visits to emergency departments in the United States 1993-1996. J Toxicol Clin Toxicol 1999; 37: 817-826.

5 Townsend E, Hawton K, Harriss L, Bale E, Bond A. Substances used in deliberate self-poisoning 1985-1997: trends and associations with age, gender, repetition and suicide intent. Soc Psychiatry Psychiatr Epidemiol 2001; 36: 228-234.

6 CDC. Web-based Injury Statistics Query and Reporting System (WISQARS TM). U.S. Department of Health and Human Services, CDC, National Center for Injury Prevention and Control, 2003. Available at http://www.cdc.gov/ncipc/wisqars/ default.htm.

7 World Health Organization. International Classification of Diseases (ICD). Available at http://www.who.int/classifications/ icd/ Retrieved 23 April 2012.

8 Güloğlu C, Kara IH. Acute poisoning cases admitted to a university hospital emergency department in Diyarbakir, Turkey. Hum Exp Toxicol 2005; 24: 49-54.

9 State Statistical Institute of Turkish Republic. Turkish statistical yearbook 1999. DIE Printing House: Ankara, 2000.

10 Bode-Jänisch S, Krüger AK, Todt M, Germerott T, Hagemeier L. Suicide in children, youths and young adults. Arch Kriminol 2011; 227: 33-42.

11 Goksu S, Yildirim C, Kocoglu H, Tutak A, Oner U. Characteristics of acute adult poisoning in Gaziantep, Turkey. J Toxicol Clin Toxicol 2002; 40: 833-837.

12 Guthrie E, Kapur N, Mackway-Jones K, Chew-Graham C, Moorey J, Mendel E, et al. Randomised controlled trial of brief psychological intervention after deliberate self poisoning. $\mathrm{Br}$ Med J 2001; 323: 135-138.

13 Ozkose Z, Ayoglu F. Etiological and demographical characteristics of acute adult poisoning in Ankara, Turkey. Hum Exp Toxicol 1999; 18: 614-618.

14 Burillo-Putze G, Munne P, Dueñas A, Pinillos MA, Naveiro JM, 
Cobo J, et al. National multicentre study of acute intoxication in emergency departments of Spain. Eur J Emerg Med 2003; 10: 101-104.

15 Viertel A, Weidmann E, Brodt HR. Cases of acute poisoning admitted to a medical intensive care unit. Dtsch Med Wochenschr 2001; 126: 1159-1163.

16 Juarez-Aragon G, Castanon-Gonzalez JA, Perez-Morales AJ, Montoya-Cabrera MA. Clinical and epidemiological characteristics of severe poisoning in an adult population admitted to an intensive care unit. Gac Med Mex 1999; 135: 669-675.

17 Yamashita M, Matsuo H, Tanaka J, Yamashita M. Analysis of 1,000 consecutive cases of acute poisoning in the suburb of Tokyo leading to hospitalization. Vet Hum Toxicol 1996; 38 : 34-35.

18 Maier R, Stieglitz RD, Marsch SC, Riecher-Rössler A. Patients in intensive care after a suicide attempt with legal drugs - risk profile and course. Fortschr Neurol Psychiatr 2011; 79: 283-289. Epub 2011 Apr 8.

19 Sein Anand J, Swiderska A. Selected data concerning acute intoxications with xenobiotics in Poland in the year 2009. Przegl Lek 2010; 67: 559-565.

20 Emerson GM, Gray NM, Jelinek GA, Mountain D, Mead HJ. Organophosphate poisoning in Perth, Western Australia, 19871996. J Emerg Med 1999; 17: 273-277.

21 Faller S, Hoetzel A. Carbon monoxide in acute lung injury. Curr Pharm Biotechnol 2012; 13: 777-786.

22 Ozturk S, Durmus I, Baltaci D, Karaman K, Kandis H. Bitter honey intoxication and hazardous arrhythmias: two cases. Konuralp Tip Dergisi [Konuralp Med J] 2011; 3: 3032.

Received March 3, 2014 Accepted after revision December 20, 2014 